\title{
SYMMETRIC NORMS AND REVERSE INEQUALITIES TO DAVIS AND HANSEN-PEDERSEN CHARACTERIZATIONS OF OPERATOR CONVEXITY
}

\author{
JEAN-CHRISTOPHE BOURIN
}

Abstract. Let $A, B, Z$ be $n$-by- $n$ matrices. Suppose $A B \geqslant 0$ (positive semi-definite) and $Z>0$ with extremal eigenvalues $a$ and $b$. Then, the sharp inequality

$$
\|Z A B\| \leqslant \frac{a+b}{2 \sqrt{a b}}\|B Z A\|
$$

holds for every unitarily invariant norm. Among the consequences, we get the operator inequality $X Z X \leqslant\left[(a+b)^{2} / 4 a b\right] Z$ for every $0 \leqslant X \leqslant I$, and some Kantorovich type inequalities (MondPečarić inequalities). Also in connection, reverse inequalities of Davis and Hansen-Pedersen characterizations of operator convexity are established. For instance, given any operator convex function $f:[0, \infty) \longrightarrow[0, \infty)$ and any subspace $\mathscr{E}$,

$$
f\left(Z_{\mathscr{E}}\right) \geqslant \frac{4 a b}{(a+b)^{2}}(f(Z)) \mathscr{E} .
$$

In passing, we point out a simplified proof of Hansen-Pedersen's inequality.

Mathematics subject classification (2000): 15A60, 47A30, 47A63.

Key words and phrases: symmetric norms, operator convex functions, operator inequalities.

\section{REFERENCES}

[1] R. BHATIA, Matrix Analysis, Springer, Germany, 1996.

[2] C. DAVIS, A Shwarz inequality for convex operator functions, Proc. Amer. Math. Soc. 8, (1957), $42-44$.

[3] F. HANSEN, An operator inequality, Math. Ann. 246, (1980) 249-259.

[4] F. HANSEN, G. K. PEDERSEn, Jensen's inequality for operator sand Lowner's Theorem, Math. Ann. 258, (1982) 229-241.

[5] F. Hansen, G. K. Pedersen, Jensen's operator inequality, Bull. London Math. Soc. 35, (2003), $553-564$.

[6] R. A. Horn, C. R. Johnson, Matrix Analysis, Cambridge Univ. Press, Cambridge, 1985.

[7] B. MOND, J. E. PEČARIĆ, A matrix version of the Ky Fan generalization of the Kantorovich inequality, Linear and Multilinear Algebra, 36, (1994), 217-221.

[8] W. F. Stinepring, Positive functions on $C^{*}$-algebras Proc. Amer. Math. Soc. 6, (1955), 211-216. 